\title{
UM ACERTO DE CONTAS ENTRE O DIREITO E A FILOSOFIA
}

\author{
AN ACCOUNTABILITY BETWEEN THE LAW AND THE PHILOSOPHY
}

\author{
${ }^{1}$ Marcelo Cacinotti Costa \\ ${ }^{2}$ Vinicius de Melo Lima
}

\section{RESUMO}

Aborda-se a prática interpretativa no Direito a partir da necessidade de um "acerto de contas" (accountability) do Direito com a Filosofia. A aplicação dos indícios formais como um método fenomenológico suficiente a valorizar o caso concreto e permitir o desvelamento do sentido das coisas aparece como alternativa. Busca-se um caminho teórico-filosófico alternativo consistente para guiar uma investigação interpretativa suficiente para o Direito. Toma-se como referencial teórico a Hermenêutica Ontológico-Existencial (Martin Heidegger e Hans-Georg Gadamer), à luz da filtragem da Crítica Hermenêutica do Direito, de Lenio Streck, procurando assinalar a relevância da "situação hermenêutica" em todo ato interpretativo.

Palavras-chave: Interpretação jurídica; Direito e Filosofia; Acerto de contas.

\begin{abstract}
It approaches to performance practice in Law from the need of an accountability between law and Philosophy. The application of formal evidence as sufficient phenomenological method to value the case and allow the unveiling of the meaning of things appears as an alternative. It searches an alternative theoretical-philosophical way consistent to guide a sufficient interpretative research for the Law. It takes as theoretical basis, the Ontological-Existential Hermeneutics (Martin Heidegger and Hans-Georg Gadamer), facing of the filtering of Hermeneutics Law Criticism of Lenio Streck, trying to point out the relevance of the "hermeneutic situation" in any interpretive act.
\end{abstract}

Key words: legal interpretation; Law and Philosophy; Accountability.

\footnotetext{
${ }^{1}$ Doutor em Direito pela Universidade do Vale do Rio dos Sinos (UNISINOS), São Leopoldo, Rio Grande do Sul, Brasil. Professor pela Universidade de Cruz Alta (UNICRUZ), Cruz Alta, Rio Grande do Sul, Brasil. Email: mccacinotti@hotmail.com ${ }^{2}$ Doutor em Direito pela Universidade do Vale do Rio dos Sinos (UNISINOS), São Leopoldo, Rio Grande do Sul, Brasil. Professor pela Universidade Luterana do Brasil (ULBRA), Canoas, Rio Grande do Sul, Brasil. Email: viniciuslima@mp.rs.gov.br
} 


\section{INTRODUÇÃO}

Necessário (re) estabelecer a relação da filosofia (hermenêutica) com o Direito. O presente artigo visa identificar a existência de uma dívida do Direito com a Filosofia, principalmente no que se refere à questão interpretativa, ou seja, relacionada à autoridade de atribuir sentido às coisas. A busca de atenuar o distanciamento existente entre Direito e Filosofia, principalmente com a série de características moderna incorporadas ao Direito (positivismo jurídico, dogmatismo, senso comum dos juristas, método científico, técnica...) se dá, no presente artigo, a partir do método dos indícios formais, como técnica filosófica utilizada para reaproximar a interpretação da fenomenologia, isto é, do caso concreto. Uma tentativa de reconciliar o Direito com a Filosofia, em um nítido "acerto de contas" (accountability) no que se refere ao intenso déficit interpretativo que permeia o Direito, herança da tradição filosófica metafísica predominante na modernidade.

Aposta-se na Filosofia Existencial de Martin Heidegger (indícios formais)como um caminho que fornece alternativas teórico-filosóficas consistentes para guiar uma investigação interpretativa suficiente para o Direito. Impõe-se traçar uma conexão entre o problema interpretativo no Direito, amplamente reconhecido por inúmeros críticos, como verificado na Nova Crítica do Direito de Lenio Streck, e a alternativa hermenêutico-filosófica dos indícios formais, pensada como alternativa hermenêutica para superar o problema do subjetivismo, intensamente presente no Direito e desenvolvida no imaginário do jurista, que acredita na discricionariedade judicial como uma consequência de eventual lacuna da lei. Dessa forma, com o intuito de demonstrar operacionalidade aos indícios formais, importante relacionar o conceito de Direito indissociável à noção de democracia e de justiça, isto é, sustentando a ideia de que o Direito e a moral são co-originários.

A preocupação central que assola a comunidade jurídica está em reafirmar a conquista de direitos e, principalmente, confirmar o avanço da era das Constituições. A defesa da democracia, portanto, constitui como um ideal a ser perseguido de maneira intensa, com o intuito de impedir que a atuação do Estado possa, de alguma maneira, comprometer o processo contínuo de democratização.

O método dos indícios formais, portanto, é transposto da filosofia hermenêutica para o Direito, com o mesmo escopo de sua criação originária, isto é, funcionar como um antídoto à adjudicação de sentido por teorias artificializadas que, ao fim e ao cabo, são prejudiciais à 
democracia, na medida em que, autoritariamente, impedem que a linguagem, na concepção gadameriana, exerça a sua primeira função: desvelar o sentido das coisas.

Daí a indagação: Qual a relação dos princípios com o Direito? A partir da afirmação da co-originariedade entre Direito e moral (Habermas), é possível dizer que os princípios não podem ser catalogados do mesmo modo como a moral se dá, isto é, eles são decorrentes da relação dialógica e intersubjetiva do mundo da vida. É o resultado da sedimentação paulatina de elementos quotidianos que formam a complexidade da vida. Por isso, não é possível que os princípios e a própria moral sejam adjudicados pela vontade de alguém.

Falar em incindibilidade entre Direito e moral é apostar na Constituição que determina a igualdade como o norte político de uma comunidade jurídica, criando mecanismos de controle do Poder do Estado, os quais se justificam na própria gênese valorativa que se instaurou a partir de uma moral político-institucional.

\section{A RELAÇÃO ENTRE O DIREITO E A FILOSOFIA}

Na obra Introdução à Filosofia (2008), de Martin Heidegger, consta no primeiro parágrafo o seguinte título: "Ser homem já significa filosofar”. Para Heidegger, a Filosofia não se trata de uma mera disciplina com a qual é possível se ocupar por alguns instantes, situação bastante comum em diversas áreas do conhecimento, caracterizada pelo estudo historiográfico de pensadores que deixaram alguma contribuição importante para a evolução do pensamento humano ao longo da história.

A concepção de Filosofia defendida por Heidegger, portanto, desenvolve-se num outro contexto de significação. Encontra-se amalgamada na própria capacidade humana de se pensar as coisas; visão diametralmente oposta à Filosofia como ramo de estudo, tratando-a como um objeto que se encontra no mundo para ser apreendido, ou, como se fosse possível, ingressar em uma nave espacial para uma longa viagem interplanetária, retornando em seguida à vida na Terra. Inexoravelmente, a concepção tradicional da Filosofia proporciona um distanciamento da verdadeira Filosofia.

O raciocínio é bastante simples: se, precisa-se ser introduzido na Filosofia, é possível concluir, portanto, que se está fora dela. Essa falsa impressão é (muito bem) utilizada porque 
produz o efeito psicológico almejado na medida em que convence a todos que, para ingressar na Filosofia, é necessário estudar historiografia. Heidegger ${ }^{3}$ aborda esse ponto, dizendo

\begin{abstract}
A questão é que não estamos de forma alguma 'fora' da filosofia; e isso não porque, por exemplo, talvez tenhamos uma certa bagagem de conhecimentos sobre filosofia. Mesmo que não saibamos expressamente nada sobre filosofia, já estamos na filosofia porque a filosofia está em nós e nos pertence; e, em verdade, no sentido de que já sempre filosofamos. Filosofamos mesmo quando não sabemos nada sobre isso, mesmo que não 'façamos filosofia'. Não filosofamos apenas vez por outra, mas de modo constante e necessário porquanto existimos como homens. Ser-aí como homem significa filosofar. O animal não pode filosofar; Deus não precisa filosofar. Um Deus que filosofasse não seria um Deus porque a essência da filosofia é ser uma possibilidade finita de um ente finito.
\end{abstract}

Dessa forma, pensar o conceito operacional dos indícios formais no Direito, como característica específica dos conceitos filosóficos, se justifica na medida em que, como ora se defende, há a necessidade de um acerto de contas do Direito com a Filosofia. A formação do pensamento jurídico é indissociável da Filosofia e da História, entretanto, por vezes, o Direito e seus lidadores se esquecem desse elemento fundamental. Daí a importância de alguns aspectos interpretativos que serão abordados ao longo deste artigo: o esquecimento do ser heideggeriano; a tradição história gadameriana; a coerência e integridade dworkiniana.

Mas no que consiste o indício formal ${ }^{4}$ (formale Anzeige) como característica específica dos conceitos filosóficos para Martin Heidegger? No pensamento heideggeriano os conceitos (filosóficos) são indícios formais e, dessa forma, apresentam a verdadeira possibilidade de se entender o que é visado pelo seu caráter fundamental. Apresenta-se, assim, o porquê (a razão de ser) dos indícios formais, os quais transitam num caminho inverso de concepções apriorísticas ou com pretensões de obter axiomas (resultados fixos). Notadamente, a postura indicativa formal possibilita à fenomenologia ${ }^{5}$ manter-se crítica e em constante movimento

\footnotetext{
${ }^{3}$ HEIDEGGER, Martin. Introdução à Filosofia. Tradução Marco Antônio Casanova. São Paulo: Martins Fontes, 2008, p. 3-4.

${ }^{4} \mathrm{O}$ termo formale Anzeige pode ser traduzido como "indicação formal" ou "indício formal", havendo uma pequena diferenciação em relação ao traduzido: primeiramente, a palavra "indicação" parece ter um uso mais abrangente do que a palavra "indício". Em segundo lugar, devido à interpretação que fazemos do conceito. Para exemplificar: dizemos que uma placa de trânsito é uma indicação de, por exemplo, um caminho para uma cidade. Mas não costumamos dizer que ela é um indício de um caminho até a cidade. Uma pegada na lama, por outro lado, pode tanto ser vista como um indício de que alguém esteve ali, mas também como uma indicação de que alguém passou ali. Parece-nos que a noção de formale Anzeige possui esse sentido mais amplo, que tanto aponta indícios como serve de indicação para o caminho a ser seguido na investigação filosófica. Optou-se em utilizar as duas formas no texto de forma indistinta.

5 “O termo 'fenomenologia' exprime uma máxima que pode ser assim formulada: 'as coisas elas mesmas!', em oposição a todas as construções que flutuam no ar, aos achados fortuitos, à assunção de conceitos só em aparência demonstrados, às perguntas só aparentemente feitas e que são transmitidas com frequência ao longo
} 
sem, contudo, render-se ao assujeitamento subjetivista ${ }^{6}$, daí a grande relevância prática no âmbito interpretativo do Direito.

No contexto da classificação da universalidade das coisas busca-se amparo em dois conceitos inicialmente apontados por Edmund Husserl: a generalização e a formalização. Necessário especificar no que consiste cada uma delas, demonstrando que nos indícios formais a referência à forma, ou ao "formal", justifica-se como preservação do sentido exigido em cada momento específico de significação, pois há uma nítida preocupação em ser responsável com o conteúdo de sentido das coisas. Notadamente que, para levar a sério este caminho interpretativo, o conteúdo material da autoridade da tradição ${ }^{7}$, lançando mão da expressão gadameriana, deve estar sempre presente, sobrepondo-se a qualquer tipo de generalização.

Heidegger trabalha a ideia de dívida $\left(S h u l d^{8}\right)$, dizendo que tudo que há no mundo, à disposição, constitui-se como uma imensa dívida que se tem com todos aqueles que já passaram por este mundo e de algum modo contribuíram para que a realidade atual seja possível. Na verdade, toda pessoa, ao nascer, já herda a linguagem da comunicação, os conceitos e, também, o sentido das coisas em seus diversos momentos históricos próprios. Aliado a tudo isso, é necessário ter consciência da continuidade do conjunto de coisas que foram herdadas, pois a produção de sentido é o resultado da inter-relação e, como tal, não é um fenômeno estático que possa desprezar o tempo, nem é uma atividade a ser delegada a alguma pessoa em específico.

das gerações como 'problemas'." Cf. HEIDEGGER, Martin. Ser e Tempo. Tradução e organização Fausto Castilho. Petrópolis: Vozes, 2012, p. 101.

${ }^{6} \mathrm{O}$ subjetivismo ou psicologismo é um dos problemas centrais identificado por Martin Heidegger em toda a sua obra, já que há uma explícita preocupação com o sentido das coisas e a relação deles com o tempo, com a mutabilidade social etc.

${ }^{7}$ Quando se fala em conteúdo de significação é possível relacionar com a compreensão-interpretação das coisas. Como se sabe, qualquer tipo de interpretação já, desde sempre, carrega um contexto de significação, herança do passado que se apresenta para todos como uma dívida (shuld), parafraseando Heidegger. Esse conteúdo de significação também compreende a moral. Elementos de moralidade que formam o entendimento no mundo e que são co-originários, por exemplo, com o direito (Habermas). São desenvolvidos na tradição e se caracterizam pela complexidade da vida, pois, como contingenciais, não podem ser trabalhados de maneira fixa.

8 "A conexão de fundamentação mostrada para os modi de ser-no-mundo que são constitutivos do conhecimentodo-mundo torna claro que, no conhecer, o Dasein ganha um novo estado-de-ser em relação ao mundo já cada vez descoberto no Dasein. Essa nova possibilidade-de-ser pode ter um desenvolvimento independente, convertendo-se numa tarefa e assumindo, como ciência, a condução do ser-no-mundo. Mas o conhecer não cria pela primeira vez um 'commercium' do sujeito com um mundo e não surge também de uma ação do mundo sobre um sujeito. O conhecer é um modus do Dasein fundado no ser-no-mundo. Daí que o ser-no-mundo, como constituição-fundamental, reclame uma interpretação prévia". Cf. HEIDEGGER, Martin. Ser e Tempo. Tradução e organização Fausto Castilho. Petrópolis: Vozes, 2012, p. 195. 
Nesse contexto, não pairam dúvidas acerca do pensamento heideggeriano estar centrado no problema decorrente da interpretação dissociada da faticidade. Daí a justificativa de um método fenomenológico ${ }^{9}$ capaz de superar o pensamento metafísico encobridor de sentido (que entifica o sentido do ser), lançando mão, portanto, do método das indicações formais ${ }^{10}$. Concomitantemente a isto, e com um caráter complementar, sem desconsiderar a formação do sentido interpretativo das coisas calcado no entrelaçamento da tradição com a visão daquilo que se apresenta no caso concreto, exsurge o sentido moral. O sentido moral de que se fala provém da natureza das pessoas (existencial) que está acima de qualquer racionalidade, como co-originário à vida humana e, consequentemente, ao Direito ${ }^{11}$. Notadamente que o aspecto moral a que se refere o presente artigo se difere de um sentido moral prático, pois, ao se "criar" padrões de moralidade ou sentidos para serem colados às coisas, ao nível da subjetividade interpretativa, como quando alguém escolhe o que irá vestir ou o que irá comer, é inexorável o autoritarismo arraigado em qualquer uma dessas escolhas, cuja padronização irá afetar sobremaneira novas e futuras escolhas, ou seja, fecha-se a capacidade de surgimento da diferença. Inexistindo a diferença, que é ontológica, fere-se de morte a capacidade de pensar o sentido das coisas, do modo como denuncia Heidegger.

\footnotetext{
${ }^{9}$ Mas será que a fenomenologia examina tudo o que se mostra, até mesmo as manchas e o próprio sarampo? Não, ela não considera entes particulares, mas aspectos do ser dos entes, aspectos que embora normalmente se mostrem de forma implícita e 'não-tematizada', podem chegar a mostrar-se tematicamente. Espaço e tempo mostram-se mas, em geral, não-tematicamente. A fenomenologia os põe em foco. A fenomenologia só é necessária porque alguns temas, especialmente o próprio ser, estão velados. Velados não porque ainda não os descobrimos ou simplesmente os esquecemos, mas porque ou estão muito próximos e familiares para que os notemos ou estão enterrados sob conceitos e doutrinas tradicionais." Cf. INWOOD, Michael. Dicionário Heidegger. Tradução Luísa Buarque de Holanda. Rio de Janeiro: Jorge Zahar, 2002, p. 66.

${ }^{10}$ Vide: COSTA, Marcelo Cacinotti. O Método dos Indícios Formais de Martin Heidegger e a Contribuição da Moral como Condição de Possibilidade para uma Adequada Aplicação do Direito. 2015. Tese (Doutorado em Direito) - Programa de Pós-Graduação em Direito, Universidade do Vale do Rio dos Sinos (UNISINOS), São Leopoldo, 2015.

${ }^{11}$ Falar em moral sempre se apresenta como uma temática bastante movediça e perigosa. Entretanto, não é possível abordar o tema da moral sem considera-la como uma espécie de mola propulsora da humanidade, independentemente de qualquer área do conhecimento, pois ela se estabelece como o objeto intencional das coisas. Inexoravelmente, os homens têm maiores inclinações para a autopreservação de si e dos outros do que o contrário, o que permite seja dito que há uma intencionalidade voltada para a preservação da vida, para evitar sofrimentos. François Jullien, ao registrar o diálogo de Mêncio com um filósofo das Luzes sobre a (a)moralidade do homem, propõe principalmente fundar a moral sobre a relação espontânea do homem diante do insuportável. E, também, ao comentar as teses defendidas pelo interlocutor e adversário de Mêncio que sustenta a maldade natural do homem, indaga: "Entretanto, há um ponto sobre o qual o adversário de Mêncio permanece evasivo: se a natureza do homem é má, de onde os sábios-reis do passado puderam tirar a moralidade?" Cf. JULIAN, François. Fundar a Moral: Diálogo de Mêncio com um filósofo das Luzes. Tradução de Maria das Graças de Souza. São Paulo: Discurso Editorial 2001, p. 72.
} 
Uma coisa é o sentido proveniente da construção intersubjetiva que se desdobra na tradição históricalconsciência histórica ${ }^{12}$ que acontece no mundo fático, outra coisa bastante distinta é a designação de um sentido (quase sempre por alguém ostentando algum tipo de poder) fruto de sua própria vontade (subjetiva). Tal pode ser comparado ao ato de olhar através de uma vidraça, cuja mirada faz com que se identifiquem objetos do outro lado da janela. Entretanto, a visão ficará cada vez mais prejudicada e, ao mesmo tempo, o observador começará a se enxergar com maior nitidez na medida em que a vidraça se torna cada vez mais opaca e menos translúcida. Dito de outro modo, quanto maior for o acúmulo de falsas percepções no ato de compreender (acúmulo de sujeira na vidraça), maior será o grau de subjetividade que se terá nesse mesmo ato (maior a nitidez do próprio observador na vidraça).

Nesse contexto, Heidegger já se encontra carregado pelo movimento da "descoberta da realidade real", sendo convocado para levar a sério o mundar (Welten) do mundo. Safranski ${ }^{13}$ se refere ao movimento da

Descoberta da realidade real, nascido no século 19, dizendo que ali descobriu-se a economia por trás do espírito (Marx), a existência mortal por trás da especulação (Kierkegaard), a vontade por trás da razão (Schopenhauer), o impulso por trás da cultura (Nitzsche, Freud) e a Biologia por trás da História (Darwin).

Portanto, a partir da conferência sobre a "vivência da cátedra", verificam-se os primeiros passos de Heidegger em direção à fenomenologia existencial ${ }^{14}$. Na conferência de inverno de 1921/22 (Interpretações Fenomenológicas de Aristóteles) ele irá denominar a

\footnotetext{
12 "Não é verdade que a questão de saber o que é se resolva sempre necessariamente, seja a favor do novo, que não tarda a se tornar obsoleto, seja a favor do que foi. Sem dúvida, o relativismo histórico tornou intelectualmente impossível o retorno efetivo (Repristinationem) de modelos anteriores de pensamento e de toda sistematização ingênua. Mas a questão filosófica não pode deixar de ser colocada. Não se pode reduzi-la à sua função social nem contorna-la, rejeitando-a ou legitimando-a a partir da crítica da ideologia. A consciência histórica transcendeu desde sempre tudo isso para retomar - embora tardiamente - a interrogação à qual damos o nome de filosofia." Cf. GADAMER, Hans-Georg. O problema da consciência histórica. Org. Pierre Fruchon; tradução Paulo César Duque Estrada, 3. ed., Rio de Janeiro: FGV, 2006, p. 15.

${ }^{13}$ SAFRANSKI, Rüdiger. Heidegger, um mestre na Alemanha entre o bem e o mal. Tradução Lya Luft, São Paulo: Geração Editorial, 2005, p. 144.

14 "Fenômeno é, portanto, aquilo que se mostra como tal, em seu mostrar-se. Antes de mais nada, isso significa: que a coisa mesma está aí como tal, não representada como quer que seja, nem é considerada de modo indireto, nem tampouco é reconstruída de alguma maneira. Fenômeno é o modo de ser objetual de algo, um modo certamente privilegiado: o estar presente de uma objetualidade por si mesma. Portanto, com isso não se decide nada absolutamente sobre a concretude das coisas, não se faz qualquer referência a algum setor determinado de coisas". Cf. HEIDEGGER, Ontologia: Hermenêutica da facticidade. Tradução de Renato Kirchner, Petrópolis: Vozes, 2012, p. 75.
} 
realidade real de "a vida fáctica". Essa vida fáctica não se sustenta mais em nenhuma instância metafísica ou religiosa, já que ela se precipita no $N a d a^{15}$ e se choca com o Dasein. ${ }^{16}$

Assim, as ideias do ser humano e de verdades infinitas com capacidades de ultrapassar os tempos e as fronteiras já não se sustentam e se tornam ilusórias diante da vida fáctica. Ilusório, também se torna o Deus que é administrado pela igreja tradicional, caracterizado como um manancial de verdades sempre à disposição.

A experiência da vida fática ${ }^{17}$ é utilizada por Heidegger ${ }^{18}$ como ponto de partida para trabalhar com a teoria do método fenomenológico enquanto indicação formal, dizendo que ela é mais do que a

\begin{abstract}
Mera experiência de tomada de conhecimento. Ela significa a plena colocação ativa e passiva do homem no mundo: vemos a experiência fática da vida apenas segundo a direção de comportamento que experimenta. Assim, "o conceito 'fático' não alcança seu significado a partir de determinados pressupostos da teoria do conhecimento, uma vez que deve ser compreendido apenas através e pelo conceito do histórico.
\end{abstract}

Portanto, não deve haver um método a priori, nem um predeterminado âmbito de investigação para o desdobramento explicativo fenomenológico. É necessário que haja um engajamento do fenomenólogo com o processo do próprio fenômeno, sem se deixar tomar só pelo conteúdo, pois o conteúdo disponível se constitui em algo que já foi apontado ou indiciado.

\footnotetext{
15 "O nada e a finitude do ser são analisados positivamente. Não podem ser vistos, na perspectiva heideggeriana, como simples negação e imposição de limite. A positividade do nada e da finitude reside precisamente no fato de o ser somente assim poder ser experimentado em sua manifestação." Cf. STEIN, Ernildo. Compreensão e Finitude: Estrutura e movimento da interrogação heideggeriana. Ijuí: Unijuí, 2001, p. 123.

16 "'A 'essencia' do Dasein reside em sua existência. Os caracteres que podem ser opostos à mostra nesse ente não são, portanto, 'propriedades' subsistentes de um ente que subsiste com este ou com aquele 'aspecto', mas modos-de-ser cada vez possíveis para ele e somente isso. Todo ser-assim desse ente é primariamente ser. Por isso, o termo 'Dasein' com que designamos esse ente não exprime o seu que, como é o caso de mesa, casa, árvore, mas o ser." Cf. HEIDEGGER, Martin. Ser e Tempo. Tradução e organização Fausto Castilho. Petrópolis: Vozes, 2012, p. 139-141, grifo do autor.

17 "Se atentarmos para a indiferença própria do experimentar fático em todas as facticidades da vida, então se torna claro um determinado sentido dominante do mundo circundante, do mundo compartilhado e do mundo próprio, a saber: tudo o que é experimentado na experiência fática da vida carrega o caráter de significância [Bedeutsamkeit]. Todo e qualquer conteúdo carrega em si esta caracterização. Com isso, porém, não está definido nada de gnosiológico, nem no sentido de realismo nem no sentido de idealismo. No modo de ser da significância, que determina o caráter de experimentar mesmo, eu experimento todas as minhas situações fáticas da vida. Isto se torna claro quando eu pergunto como eu mesmo me experimento na experiência fática da vida: sem teorias!" Cf. HEIDEGGER, Martin. Fenomenologia da Vida Religiosa. Tradução de Enio Paulo Giachini, Jairo Ferrandin e Renato Kirchner. Petrópolis: Vozes, 2010, p. 17.

${ }^{18}$ HEIDEGGER, Martin. op. cit., p. 14.
} 


\section{OS INDÍCIOS FORMAIS COMO UM ANTÍDOTO FILOSÓFICO À ENTIFICAÇÃO DO SER}

O termo fenomenologia cunhado na Filosofia, muito antes de Heidegger, com ele ganha novos contornos, pois exprime uma oposição a tudo que não possui uma base sólida de fundamentação, achados fortuitos e mirabolantes e assunção de conceitos de forma rasa e superficial. E esse é um verdadeiro problema para o Direito. Embora Heidegger não tenha escrito nenhuma linha sobre questões jurídicas típicas, sua filosofia fenomenológica tem aplicabilidade em todos os fenômenos da facticidade, na medida em que o que denominou de poder-ser-entendido-por-si-mesmo, nada mais é do que lançar luz sobre o procedimento.

Como referido, mesmo sem nada abordar sobre o Direito, é nítida a preocupação da filosofia existencial em relação à interpretação, refém da relação sujeito-objeto (subjetivista). ${ }^{19}$ Dessa forma, alguns juristas preocupam-se com uma crise instaurada no Direito, de cariz filosófico. Lenio Streck $^{20}$ aborda o problema da filosofia da consciência, dizendo que não é possível sustentar qualquer forma de discricionariedade judicial nesse momento histórico, uma vez que a discricionariedade está ligada ao subjetivismo (portanto, sujeito-objeto), avesso ao paradigma intersubjetivo. Estado Democrático de Direito e discricionariedade são incompatíveis - e essa questão é fulcral.

No pensamento heideggeriano, a epistemologia não aparece como necessária. O que realmente importa é criar condições de possibilidade para que o significado possa surgir, principalmente porque a situação de estado de consciência natural é utópica e irreal - desde já sempre se opera a transcendência - pois seria muita ingenuidade continuar acreditando, como Kant, que se vive numa atividade natural, ou que se faz necessário de um processo para construir um mundo transcendental. No ponto, pertinente a seguinte passagem

O Dasein, em sua familiaridade com a significatividade, é a condição ôntica da possibilidade de poder ser descoberto o ente que vem-de-encontro em um mundo no modo-de-ser do conjuntar-se (utilizabilidade) e que pode, assim, anunciar-se em seu em-si. O Dasein é, como tal, cada vez 'este' e, com seu ser, fica já essencialmente

\footnotetext{
19 “O que primeiramente deve ser evitado é o esquema: que há sujeitos e objetos, consciência e ser; que o ser é objeto do conhecimento; que o ser verdadeiro é o ser da natureza; que a consciência é o 'eu penso', portanto, egoico, a egoidade, o centro dos atos, a pessoa; que os eus (pessoas) possuem diante de si: entes, objetos, coisas da natureza, coisas de valor, bens. Enfim, que a relação entre sujeito e objeto é o que se deve determinar e que disso deve ocupar-se a teoria do conhecimento." Cf. HEIDEGGER, Ontologia: Hermenêutica da facticidade. Tradução de Renato Kirchner. Petrópolis: Vozes, 2012, p. 87.

20 STRECK, Lenio Luiz. Verdade e Consenso: Constituição, Hermenêutica e Teorias Discursivas. Da possibilidade à necessidade de respostas corretas em direito. São Paulo: Saraiva, 4. ed, 2011, p. 65
} 
descoberta uma conexão-de-utilizável - o Dasein, na medida em que é, já se remeteu cada vez a um 'mundo' que vem-de-encontro; a seu ser pertence essencialmente esse ser-remetido. Mas a significatividade ela mesma, com que o Dasein já está cada vez familiarizado, traz consigo a condição ontológica da possibilidade de que o Dasein que-entende possa abrir, como interpretante, algo assim como 'significações', as quais por sua vez fundam novamente o ser possível da palavra e da língua. ${ }^{21}$

Considerando-se que o Dasein está jogado-no-mundo em meio a possibilidades, qualquer exposição do tipo lógico-dedutiva ou meramente teórica, bastante comum no cotidiano jurídico, caracterizada pelo horizonte previamente definido por matriz de sentido, fará o Direito soçobrar. Nesse aspecto, inexiste uma inter-relação de produção de sentido frente ao movimento da faticidade, que, ao fim, ocupa uma posição de somenos importância.

A experiência da vida fática, portanto, é condição de possibilidade para operar com o método fenomenológico enquanto indicação formal. ${ }^{22}$ Não deve haver âmbito predeterminado de investigação para o desdobramento explicativo fenomenológico. A filosofia formalmente indiciadora não é, assim, apenas uma teoria, mas muito mais uma realização de vida na travessia do tempo.

Na visão de Ernildo Stein ${ }^{23}$, as proposições de Ser e Tempo possuem um caráter formal. Pretendem descrever as estruturas, as relações que constituem o mundo. Mas, enquanto essas estruturas são denominadas existenciais e não apenas ontológicas, seu sistema não se descola do mundo da vida. Essa articulação entre estrutura e existência (aliança aparentemente impossível) dá às proposições heideggerianas um caráter formal ambivalente. É uma transcendentalidade - condição de possibilidade - que se pretende expor, mas não a partir da consciência nem a partir de um metadiscurso.

\footnotetext{
${ }^{21}$ HEIDEGGER, Martin. Ser e Tempo. Tradução e organização Fausto Castilho. Petrópolis: Vozes, 2012a, p. 261.

22 "Para isso trabalha o indício formal. Este pertence, como momento teórico, à explicação fenomenológica mesma. Por que é chamado de "formal"? O formal é algo relativo à referência. Indício deve indicar antecipando a referência do fenômeno - num sentido negativo, porém, como se tratasse de uma advertência! Um fenômeno deve ser dado previamente de tal modo que seu sentido referencial fique em suspenso. Deve-se evitar assumir o seu sentido referencial seja originariamente teórico. A referência e a realização do fenômeno não se determinam, de antemão, mas estão em suspensão, à espera de concretização. Esta é a uma posição que se opõe frontalmente à ciência. Não existe nenhuma inserção num campo temático, mas, em contrapartida, o indício formal é uma defesa [Abwehr], um asseguramento [Sicherung] prévio de modo que o caráter realizador ainda permanece livre. A necessidade desta medida de precaução procede da tendência decadente da experiência fática da vida que ameaça constantemente a decair e a se desviar, extraviando-se para a objetividade e da qual, em contrapartida, precisamos evidenciar os fenômenos." Cf. HEIDEGGER, Martin. Ser e Tempo. Tradução e organização Fausto Castilho. Petrópolis: Vozes, 2012, p. 59.

${ }^{23}$ STEIN, Ernildo. Paradoxos da Racionalidade. Porto Alegre: Pyr Edições, 1987, p. 43.
} 
A antecipação de sentido e a posição prévia têm relevância ímpar na fixação de sentido do método das indicações formais, pois a partir delas é que se possibilita criar uma perspectiva a respeito de um âmbito determinado, de uma visão de mundo. ${ }^{24}$

Notadamente que falar em sentido significa, de uma forma ou de outra, cair no problema da conceituação ou do nominalismo. ${ }^{25} \mathrm{E}$, isso não representa, à primeira vista, um problema, entretanto, traz uma consequência inexorável que é a da definição como algo dado e exaurido. Manter sempre presente a ideia de que o mundo empírico é composto de formas prévias que podem ser comparadas aos signos, com clara e nítida tarefa de tornar as coisas no mundo compreensíveis, mas, contudo, o contexto de sentido que dará o preenchimento dessa moldura é auferido somente no caso concreto e em meio à singularidade própria das pessoas, ou seja, na facticidade.

Diferentemente do que acontece noutros campos, onde a ambivalência ganha mais espaço, bem característico no Direito, por exemplo, onde o contraditório é elemento de validade, aliado ao fato de que as definições são realizadas para coisas que não possuem a relação de significação causal-instrumental decorrente da manualidade, como no exemplo do martelo. $\mathrm{O}$ instrumento martelo, como já referido, sempre será um martelo e sua atribuição para o mundo prático não irá variar dentro daquilo que sempre foi e será a sua utilidade.

No Direito, a relação que há entre conceitos (jurídicos) e o seus sentidos, pode-se dizer, tem outra dinâmica de significação, o que permite, inclusive, tratar regras jurídicas e decisões judiciais como indícios formais, suficiente para possibilitar uma textura interpretativa

\footnotetext{
24 “Concepção prévia e método, caminho encetado, jorram da mesma fonte de sentido. Sabendo-se isso, há que deixar em aberto (offenzuhalten) a fixação de sentido de método em favor de um significado formal indiciador, por exemplo, caminho para descrições e determinações propriamente concretas. Uma vez efetuado e consumado o processo da indiciação formal de significado por concretizações próprias singulares, consumações singulares de caso a caso, então simultaneamente são anulados os aspectos antecipatórios na dinâmica da realização em processo." Cf. SCHNEIDER, Paulo Rudi. Notas sobre a relação entre indiciação formal e experiência. Natureza Humana, São Paulo, v. 14, n. 1, p. 392, 2012.

${ }^{25}$ Tanto as análises de Kripke, Donellan, como as de Frege, Searle e Strawson nos deixam em todo o caso concluir que a "concepção 'intencionalista' tradicional da conexão entre palavras e o mundo parece ser falsa em casos individuais e filosoficamente comprometedora". É por isso que afirma Rorty que "na nova filosofia da linguagem 'impura' praticamente já se tornou dogma que as doutrinas que soam 'idealisticamente' de Quine, Wittgenstein, Sellars, Kuhn e Feyerabend devem ser refutadas através do retorno ao princípio básico da semântica, derrubando a teoria referencial 'intencionalista' de Frege para em seu lugar colocar algo melhor. A ideia básica é que sempre estaremos em "contato com o mundo" quando o mundo se nos estende para nós vinculando a linguagem com as relações fáticas (causais por exemplo), enquanto segundo a velha concepção fregueana sempre subsiste o perigo de que possivelmente podemos perder o mundo ou com ele nunca estávamos efetivamente conectados" (Rorty, 317). STEIN, Ernildo. Paradoxos da Racionalidade. Porto Alegre: Pyr Edições, 1987, p. 117-118.
} 
"referencial" 26 , pois o conteúdo de significação poderá se ampliar ou se restringir de acordo com o conjunto de fatores concretos (moralidade constitucionalmente reconhecida), sedimentados por uma série de influências de ordem histórica, econômica ou social e assim por diante, como poderia dizer o saudoso professor Ovídio A. Baptista da Silva ${ }^{27}$ ao mencionar o problema interpretativo condicionado ao pensamento ideológico.

Aí está o ponto de toque com o a filosofia heideggeriana preocupada com a ambivalência do mundo da vida (faticidade); ao passo que o tratamento tradicional e ideológico legatário da filosofia tradicional, como acima referido por Ovídio Baptista, despreza o que a vida possui de mais fértil que é o caso concreto e as vicissitudes do quotidiano. $^{28}$

É possível afirmar que existem condições e possibilidades para se chegar ao fundamento adequado de cada conceito (jurídico). É certo que no Direito a relação que se dá entre o objeto e o seu sentido é bastante distinta da relação de sentido que se dá no mundo da ciência ou, até mesmo, da típica relação binária de significação que ocorre no quotidiano empírico, onde a simples mirada em direção a um objeto, com carga suficiente de sentido, já é possível concluir sobre a sua função, ou seja, embora repetindo, ao se deparar com um objeto como o martelo (o sentido de martelar está exaurido em si mesmo).

No âmbito jurídico, ao contrário, o conteúdo de significação das coisas carrega a complexidade como característica da ambivalência do mundo da vida, o que já evidencia a necessidade de ser preservado o elemento dialógico e intersubjetivo que caracteriza as

\footnotetext{
${ }^{26}$ Importante dizer, novamente, que a chamada "abertura" de sentido, que também é responsável pela capacidade do direito em acompanhar as transformações sociais, não quer dizer que a interpretação jurídica seja compatível com arbítrios interpretativos oriundo da consciência do intérprete.

27 "Ao contrário do pensamento utópico, cujo componente ideal é um estado de inconformismo com a ordem social vigente, a ideologia congela a história como uma 'segunda natureza', apresentando-a como espontânea e, assim, inalterável. O pensamento conservador, diz Eagleton, imagina que aquilo que 'foi verdadeiro', sempre e em toda parte o será, devendo ser tido como 'inato à natureza humana'. A marca do pensamento ideológico expressa-se frequentemente com um 'é claro', 'nem seria difícil explicar'. De tão claras que as coisas lhe parecem, o pensamento ideológico é incapaz de curvar-se criticamente sobre si mesmo." Cf. SILVA, Ovídio A. Baptista da. Processo e Ideologia: o paradigma racionalista. Rio de Janeiro: Forense, 2006, p. 23.

28 "O contexto da formação desse método ajuda a esclarecer sua intenção e uso. Heidegger estava interessado em desenvolver uma filosofia que pudesse abarcar a vida concreta. O modo como a filosofia da tradição abordava as questões parecia não levar em conta a realidade dada, com todas suas contingências e cotidianidades. O tratamento conferido ao conhecimento tendia a focar no objeto e a caracterizá-lo de um modo totalmente teórico. $\mathrm{O}$ próprio sujeito do conhecimento era descrito em filosofia geralmente como um sujeito "descarnado" e separado do mundo dos objetos (o que gerava uma dualidade que dificilmente permitiria reconciliação). $\mathrm{O}$ caráter histórico e temporal presente na compreensão era muitas vezes simplesmente ignorado, ou então não suficientemente desenvolvido, a ponto dos filósofos não perceberem a base na qual repousava a teoria por eles formulada." Cf. MISSAGGIA, Juliana Oliveira. Indicações formais e a origem do método de Ser e Tempo. Revista Eletrônica Intuitio/PUCRS, Porto Alegre, v. 3, n. 1, p. 48, jun., 2010. Disponível em: <http://revistaseletronicas.pucrs.br/ojs/index.php/intuitio/article/view/5814>. Acesso em: 25 ago. 2014.
} 
relações sociais e humanas. Portanto, o modo adequado de chegar ao fundamento, ao contrário do pensamento subjetivo ou do raciocínio silogístico-matemático presente no imaginário dos juristas, ${ }^{29}$ passa necessariamente pela análise das circunstâncias do caso concreto. $\mathrm{O}$ intérprete deve permitir que a linguagem ${ }^{30} \mathrm{o}$ interpele e se manifeste, sem jamais desconsiderar a tradição e o contínuo fluxo da vida.

Daí a importância para o processo interpretativo do método dos indícios formais que contém relevante contribuição: apontar para uma direção exata sem que pairem dúvidas sobre qual o meu lugar de fala. Essa função denominada de referencial serve para evitar que se confunda, por exemplo, direito com a lei, traço, aliás, bastante característico no senso comum dos juristas.

\section{A CONSTITUIÇÃO DO DIREITO COMO INTERPRETAÇÃO MORAL}

Acredita-se que a designação da palavra moral está relacionada a um contexto de significabilidade que, desde sempre, está presente no contexto de aplicação do Direito. Ideia diametralmente oposta à designação moral (prática) passível de adjudicação interpretativa recorrente do predomínio da subjetividade.

A moralidade jurídica referida tem relação íntima com responsabilidade, decorre do compromisso que todas as pessoas têm de levar a sério o ato interpretativo, de modo a valorizar o compromisso democrático sem cair em arbitrariedades. Também pode ser relacionada ao cuidado, como característica humana, decorrente da própria relação que o homem tem consigo mesmo e com os outros. Nisso, é possível registrar a contribuição de François Julian $^{31}$ em relação à humanidade e à solidariedade

\footnotetext{
${ }^{29}$ O Direito é tratado como um objeto de adorno. Um objeto imóvel e estático cujas propostas de compreensão estão ligadas a uma visão distanciada da realidade, já que a concepção apriorística de conhecimento e interpretação privilegiam métodos para se chegar à justiça e ou à verdade. Trata-se do Direito como se ele estivesse à disposição da vontade do intérprete, invertendo-se, portanto, o curso do rio.

${ }^{30}$ Portanto, na hermenêutica filosófica, a ferramenta não é decisiva, porque na linguagem existe algo muito além do enunciado, isto é, o enunciado não carrega em si mesmo o sentido, que viria a ser "desacoplado" pelo intérprete. $\mathrm{Na}$ interpretação sempre fica algo de fora, o não dito, o inacessível. É assim que "ser que pode ser compreendido é linguagem" (Sein, das verstanden werden kahn, ist Sprache), dirá Gadamer. Cf. STRECK, Lenio Luiz. Verdade e Consenso: Constituição, Hermenêutica e Teorias Discursivas. Da possibilidade à necessidade de respostas corretas em direito. São Paulo: Saraiva, 4. ed, 2011, p. 285.

${ }^{31}$ JULIAN, François. Fundar a Moral: Diálogo de Mêncio com um filósofo das Luzes. Tradução de Maria das Graças de Souza. São Paulo: Discurso Editorial, 2001, p. 95.
} 
Que todos os seres que existem fora de mim encontram-se também implicados em mim, que me encontro pois implicitamente implicado neles, isto basta para pensar o humano: a moral consistirá simplesmente em desenvolver por meio de minha conduta esta implicação inicial, em tornar explícita em minha existência a integração que está no princípio da vida; mostrar-se humano, como se deve ser, é tornar efetiva em torno de mim esta sensibilidade aos outros - que é virtual em mim.

É necessário estar atento à experiência herdada histórica, social e culturalmente para integrar qualquer processo interpretativo, mesmo porque é na tradição que se concretizam os valores éticos e morais de um grupo social. Entretanto, constitui-se tarefa perigosa utilizar pré-juízos de forma geral e indiscriminada, ou seja, sem suspendê-los frente ao que Gadamer denominou de "fusão de horizontes", interrogando o pressuposto interpretativo frente à situação concreta. Nesse aspecto, Gadamer ${ }^{32}$ comenta a relação da aplicação do Direito com as modificações sociais e históricas, dizendo

Um positivismo legal que quisesse reduzir toda a realidade jurídica ao direito positivo e sua aplicação correta dificilmente encontraria hoje alguém que o adotasse. A distância existente entre a generalidade da lei e a situação jurídica concreta, no caso particular, é insuperável por essência. Também, não parece ser suficiente pensar à maneira de uma dogmática ideal, segundo a qual a força produtora de direito inerente ao caso particular seria predeterminada logicamente, no sentido de que fosse possível imaginar uma dogmática que pudesse conter, pelo menos potencialmente, todas as verdades jurídicas geralmente possíveis dentro de um sistema coerente.

A posição do intérprete não é fixa, não há posição neutra, pois, a interrogação ou o entendimento acontece na linguagem, ${ }^{33}$ já que o local de interpretação é por si só o efeito do passado sobre o presente (consciência histórica efeitual). A soberania do sujeito é fictícia, pois o intérprete é pouco mais que o efeito da tradição ao invés de sujeito controlador.

O Direito dissociado da moral tende a não dar conta do seu papel, que é mínimo, pois, na medida em que o paradigma social se volta para o agir responsável e para a ética do cuidado, a tradicional tensão do cidadão com o dever ser se atenua no desenvolvimento do

\footnotetext{
${ }^{32}$ GADAMER, Hans-Georg. Verdade e Método II: Complementos e índice. Tradução de Ênio Paulo Giachini. 5. ed. Petrópolis: Vozes, 2010, p. 465-466.

33 "Pensando o sentido da linguagem como linguagem, temos de renunciar aos procedimentos de há muito habituais de se considerar a linguagem. Não podemos mais considerar a linguagem segundo as representações tradicionais de energia, atividade, trabalho, força do espírito, visão de mundo, expressão, pelos quais assumimos a linguagem como um caso particular de algo universal. Ao invés de esclarecer a linguagem como isso ou aquilo e assim fugirmos da linguagem, o caminho para a linguagem deve permitir a experiência da linguagem como a linguagem. Ao discutir a essência da linguagem, agarra-se a linguagem num conceito, mas o que a agarra é um outro elemento e não a linguagem ela mesma. Quando, porém, se atenta à linguagem como a linguagem, a linguagem nos obriga a trazer, para a linguagem como linguagem, o que pertence à linguagem." Cf. HEIDEGGER, Martin. A Caminho da Linguagem. Tradução de Márcia Sá Cavalcante Schuback, 5. ed. Petrópolis: Vozes, 2011, p. 199.
} 
sentimento da alteridade, que não se resume tão-somente em colocar-se no lugar do outro, mas, principalmente, em estar ciente de que todos os atos comissivos ou omissivos terão algum reflexo no mundo. O agir moral não admite, por exemplo, que o intérprete não tenha compromisso com o agir responsável, impossibilitando que sequer se pergunte acerca de tal encargo. O ponto, pertinente é a passagem bíblica, na qual Caim é questionado sobre o paradeiro de seu irmão Abel. ${ }^{34}$

\begin{abstract}
Não é por acaso que todos são responsáveis (guardiões) por seus irmãos. E se permanece uma pessoa moral enquanto não se pergunta por uma razão especial para sê-lo. Ora, o bem-estar do meu irmão depende do que eu faço ou do que deixo de fazer. A moralidade se relaciona com a assunção e com o reconhecimento dessa dependência, aceitando o encargo e a responsabilidade que lhe é inerente, ou seja, bastando que se viva em comunidade. ${ }^{35}$
\end{abstract}

A expressão "guardião de meu irmão" se relaciona com toda a ação ou omissão que de alguma forma interfira na melhoria das condições de vida das pessoas, seja pelo zelo e pelo cuidado que se deve ter com o erário, com o cumprimento das obrigações de caráter coletivo, com respeito à lei (Constituição), preservação do meio-ambiente, desenvolvimento sustentável, etc.

A metáfora utilizada no trecho bíblico do diálogo de Deus com Caim retrata a própria relação do homem com questões de grande indagação coletiva ou social, como o próprio Estado de bem-estar social, cada vez mais fragilizado. ${ }^{36}$ A moralidade é co-originária do Direito e, como não poderia deixar de ser, na lição de Streck, ${ }^{37}$ é "determinante para o constitucionalismo", como um dos principais elementos para um modelo de Estado democraticamente ético.

Também, o tema central de abordagem permeia todo o contexto de formação legislativa (Teoria da Legislação) ${ }^{38}$ e aplicação (Teoria da Decisão Judicial), ${ }^{39}$ principalmente porque a

\footnotetext{
34 "Em passagem bíblica, Deus perguntou a Caim onde estava Abel, Caim replicou, zangado, com outra pergunta: ‘sou por acaso o guardião do meu irmão?” Cf. BAUMAN, A Sociedade Individualizada: vidas contadas e histórias vividas. Tradução José Gradel. Rio de Janeiro: Jorge Zahar, 2008, p. 96.

35 BAUMAN, Zygmunt. op. cit., p. 96.

${ }^{36}$ Ver: BAUMAN, Zygmunt. op. cit., p. 109.

${ }^{37}$ STRECK, Lenio Luiz. Jurisdição Constitucional e Decisão Jurídica. 3. ed. São Paulo: Revista dos Tribunais, 2013, p. 114.

38 "Por todo es que el vínculo de las dichas racionalidades linguísticas o jurídico-formales con la racionalidad ética es muy intenso. Y por ello es que la creación dela ley debe fundarse objetivamente, pues hay valores objetivos a los cuales necesariamente el legislador debe remitirse em razón da la tesis de la unidad de valor. Y la ley, por tanto, tendrá como su sostenedor el fundamento moral." Cf. HOMMERDING, Adalberto Narciso. Teoría de La legislación y Derecho como Integridad. Curitiba: Juruá, 2012, p. 215.
} 
moral, como já referido, é co-originária do Direito. Portanto, o Direito precisa se conformar com A Força Normativa da Constituição, ${ }^{40}$ assim como, manter a coerência e a integridade, ${ }^{41}$ pois se constituem posturas éticas necessárias para qualquer Estado que se anuncia como democrático ${ }^{42}$.No ponto, ao tratar dos Direitos Fundamentais Sociais, Vinícius Melo Lima menciona que eles "não podem depender da sorte ou do acaso que decorrem do ponto de vista da 'consciência do justo' por parte do julgador, em nítida afronta ao ideal de integridade e à leitura moral do Direito" 43 .

Na linha de Konrad Hesse, é necessário apostar na autonomia da Constituição e na sua força normativa, que contém uma moralidade jurídica, por exemplo, impedindo que as normas constitucionais se confundam com normas meramente programáticas, já que o conceito de constitucionalismo atravessou o último milênio e com ele se construiu um sentido moral (de efetividade) ao longo de toda a história de conquistas de direitos. ${ }^{44}$ Ora, apostar na Constituição é reafirmar os princípios basilares da sociedade, sem medo de que o fundamento principal a ser zelado possa ser fragilizado ou corrompido por outros protagonistas sociais, tais como a economia (utilitarismo) e a política.

Para Heidegger, trabalhar com um modelo interpretativo hermenêutico-existencial, isto é, valorizando a faticidade e em constante indagação a respeito do sentido do ser das coisas se

\footnotetext{
39 "Implica um rigoroso controle das decisões judiciais, porque se trata, fundamentalmente, de uma questão que atinge o cerne do Constitucionalismo Contemporâneo: a democracia. Se ficarmos a mercê da razão prática para superar o formalismo exegetista, estaremos substituindo o juiz boca-da-lei pelo "proprietário dos sentidos da lei". Cf. STRECK, Lenio Luiz. Jurisdição Constitucional e Decisão Jurídica. 3. ed. São Paulo: Revista dos Tribunais, 2013b, p. 328.

40 "A norma constitucional não tem existência autônoma em face da realidade. A sua essência reside na sua vigência, ou seja, a situação por ela regulada pretende ser concretizada na realidade. Essa pretensão de eficácia (Geltungsanspruch) não pode ser separada das condições históricas de sua realização, que estão, de diferentes formas, numa relação de interdependência, criando regras próprias que não podem ser desconsideradas." Cf. HESSE, Konrad. A Força Normativa da Constituição. Tradução Gilmar Ferreira Mendes. Porto Alegre: Sergio Antônio Fabris Editor, 1991, p. 14-15.

41 "Uma sociedade política que aceita a integridade como virtude política se transforma, desse modo, em uma forma especial de comunidade, especial num sentido que promove a autoridade moral para assumir e mobilizar monopólio de força coercitiva. [...] A integridade protege contra a parcialidade, a fraude e outras formas de corrupção oficial, por exemplo." Cf. DWORKIN, Ronald. O Império do Direito. Tradução Jeferson Luiz Camargo. 3. ed. São Paulo: Martins Fontes, 2014, p. 228.

42 Veja-se que o grau de democracia de uma nação pode ser quantificado pelo nível de autonomia da Constituição frente aos atos de governo, principalmente pelo controle de constitucionalidade e pela sua capacidade e efetividade normativa, totalmente incompatível com normas programáticas.

${ }^{43}$ LIMA, Vinicius de Melo. Teoria Hermenêutica da Responsabilidade Decisória: Direitos Sociais entre Ativismo Judicial e Decisão Jurídica Democrática. Curitiba: Juruá, 2016, p.229.

44 "O constitucionalismo, pelas suas características contratualistas, vai se firmar como uma teoria que tem a Constituição como lei fundamental apta a limitar o poder, mas, mais do que isso, limitar o poder em benefício de direitos, os quais, conforme a evolução histórica, vão se construindo no engate das lutas políticas (direitos de primeira, segunda e terceira dimensões, que demonstram as diversas fases pelas quais passou o Estado de Direito a partir da revolução francesa até os dias atuais)." Cf. STRECK, Lenio Luiz. Jurisdição Constitucional e Decisão Jurídica. 3. ed. São Paulo: Revista dos Tribunais, 2013, p. 349.
} 
revela uma atitude responsável e, portanto, moral. Embora alguns possam afirmar que a filosofia heideggeriana é alheia à política, ao direito etc., tal afirmação não se sustenta em face da precedência ontológica fundamental que há entre a Filosofia e qualquer prática humana. Miguel de Beistegui ${ }^{45}$ sintetiza a incindibilidade da Filosofia, afirmando que

No es sólo una cuestión de ser indiferente a la política, dado que la precede desde el punto de vista ontológico. La precedencia ontológica de la filosofia a la política, el orden de fundamentación que existe entre ambas, es quizá lo que se encuentre en la fuente misma de la política, en esencia ambígua e incluso doble, de Heidegger.

Ao contrário da tentativa de teorização do mundo da vida, bastante clara no contexto racionalista e matematizante predominante na metafísica, Heidegger projeta o existir humano a partir da finitude do horizonte temporal. Como Ressalta Zeljko Loparic, 46 "O estar-aí vale, diz Heidegger, 'como um ente de que a gente deve se ocupar no sentido de realizar valores ou de cumprir normas'. (1927, p. 293). Agir moralmente significa tornar presente um predicado ou um estado de coisas".

O problema está na questão do pensar representacional capaz de encobrir o existir humano, pois, para Heidegger o agir moral se distingue do agir causal, direcionado especificamente para algo. Na verdade, o agir moral heideggeriano se distingue pelo cuidado, pela responsabilidade e, principalmente, pela valorização da tradição histórica no exercício interpretativo. Loparic $^{47}$ refere, dizendo

Heidegger não deixa dúvida: para ele, em Ser e Tempo, o agir moral, prescrito pela ética tradicional, é um agir causal, isto é, do mesmo tipo do agir técnico. Temos aqui uma das razões por que Heidegger evita usar o termo 'ação' e o substitui por 'ocupação preocupada', expressão que designa o atuar humano livre do princípio da causalidade. De nada adianta objetar, com Habermas, que as regras do agir moral são dadas pela razão prática e não pela instrumental. Heidegger responderá que, desde Kant, o tipo das leis morais é o mesmo que o das leis da natureza; que a razão instrumental e a razão prática são, no essencial, a mesma razão, definida pela obediência ao princípio de fundamento. A assim chamada 'razão ampliada', constituída pelo distanciamento 'crítico' do saber meramente estratégico e explicitada por procedimentos comunitários em situações livres de dominação, a partir de contexto do mundo da vida, é tão presentificante quanto a 'razão mutilada' dos positivistas. Ambas operam com o ente entendido no horizonte da metafísica da presentidade, acessível unicamente na representação. Uma ética que conseguisse explicitar, representar, 'máximas univocamente calculáveis' da ação, encobriria, da mesma maneira como o faz a técnica, a acontecência do agir humano no sentido próprio (1927, p. 294).

\footnotetext{
${ }^{45}$ BEISTEGUI, Miguel de. Heidegger y lo Político. Buenos Aires: Prometeo Libros, 2013, p. 38.

${ }^{46}$ LOPARIC, Zeljko. Ética e Finitude. São Paulo: EDUC, 1995, p. 53.

${ }^{47}$ LOPARIC, Zeljko. op. cit., p. 54-55.
} 
Portanto, a filosofia heideggeriana aponta para uma ética, ao contrário do que muitos poderiam dizer, pois alerta para o ter-que-ser (Zu-sein-haben), "Eu sou”, em Ser e Tempo, quer dizer "eu estou habitando", "eu estou morando" um mundo que eu mesmo abro e projeto.

O agir, portanto, não significa produzir efeitos, mas, ao contrário, pressupõe deixar surgir o ente causal na situação concreta (Augenblick), implementar sentidos impulsionado pela culpa do não ser. Somente o agir não causal e despreocupado com o resultado torna o homem responsável (verantwortlich). Responsável, diz Loparic, ${ }^{48}$

\begin{abstract}
No sentido de ser, ele mesmo, a 'condição de possibilidade' do 'moralmente' bom e mau, isto é, 'da moralidade em geral e das suas formulações facticamente possíveis' (p. 286). A moralidade não pode, portanto, determinar o ser culpado, porquanto ela mesma o pressupõe. $\mathrm{O}$ homem existe culpado antes de existirem as normas, antes mesmo de ter feito qualquer coisa.
\end{abstract}

A relação de estar-em-débito e o dever moral não significa obrigação de pagar uma dívida. Na verdade, o reconhecimento do débito é condição de possibilidade para que todo o agir humano interpretativo possa ser descrito como um agir moral. Somente haverá responsabilidade do intérprete na medida em que considerar o peso da tradição, relação metafórica de uma dívida que não precisa ser paga, mas que não pode ser desprezada.

\title{
CONCLUSÃO
}

À luz do que foi exposto, principalmente diante do problema interpretativo que há no Direito, assim como da necessidade de caracterização do Direito como indício formal e da impossibilidade de sua aplicação dissociada da perspectiva moral, é possível definir algumas conclusões que deixam claro os pressupostos metodológicos que sustentam a reflexões deste trabalho, senão vejamos:

Em tempos de crise no Direito, impõe-se estreitar com ele a relação da filosofia hermenêutica. Utilizou-se, para tanto, os indícios formais, como método filosófico suficiente para reaproximar a interpretação jurídica da fenomenologia da faticidade, isto é, da aplicação do Direito do caso concreto.

O enfoque não visa unicamente identificar o caráter referencial do Direito, reclassificando-o como indicação de algo (ainda não exaurido, pois dependente do caso

${ }^{48}$ LOPARIC, Zeljko. Ética e Finitude. São Paulo: EDUC, 1995, p. 62. 
concreto para tanto), mas passa, também, pela análise da prática interpretativa do Direito como uma atitude de natureza moral.

A preocupação central que assola a comunidade jurídica está em reafirmar a conquista de direitos e principalmente confirmar o avanço da era das Constituições. A defesa da democracia, portanto, se constitui como um ideal a ser perseguido de maneira intensa, com o intuito de evitar que a atuação do poder pelo Estado possa comprometer o processo contínuo de democratização. Tal preocupação não é nova e se apresenta bem evidente nos modelos de Controle de Constitucionalidade, caudatários de uma nítida preocupação com a democracia e com o abuso do poder estatal.

Para além disso, há um sentido moral que provém da natureza das pessoas (existencial) e que constitui o âmago das instituições e da própria sociedade, algo que transcende qualquer racionalidade, pois, pela linguagem, exsurge como co-originário à vida humana e, consequentemente, ao Direito.

Daí a importância da abordagem dos indícios formais como parâmetro filosóficointerpretativo à aplicação do Direito. Se há um problema semântico (fundamento) na aplicação da regra jurídica, impõe-se sua definição como indicação de algo, isto é, sem o conteúdo exaurido. Indicar significa dar uma direção mínima sem, contudo, definir qual o sentido prévio de algo, o qual somente será possível na aplicação, dando-se ênfase ao caso concreto como o lugar de ocorrência da complexidade da vida.

Afirmar que o Direito deve se conformar ao método dos indícios formais significa dizer que, não só leis, regras e demais institutos normativos, que se encontram pairando de forma estática sob a órbita jurídica de uma comunidade, são indicativos de algo, mas, também, a própria normatização do Direito, decorrente da aplicação jurídica feita pelos tribunais, se conforma na sua natureza meramente indicativa.

Não há como conceber qualquer forma de definição (jurídica), independentemente de sua formação, que não seja uma mera indicação de sentido, repita-se: indicação. Indicar não quer dizer determinar, ao contrário, significa dizer que o mundo se encontra em um contínuo fluxo temporal, e o pano de fundo interpretativo será sempre o caso concreto, também denominado de faticidade.

A moralidade do Direito, a racionalidade do Direito e a sua autonomia não resultam apenas do fato da positivação de exigências morais de racionalização nas Constituições. 
Resultam, principalmente, da circunstância de haver procedimentos instituídos para a autoregulação e autocontrole da fundamentação do Direito de acordo com esses padrões morais de racionalidade.

\section{REFERÊNCIAS}

BAUMAN, A Sociedade Individualizada: vidas contadas e histórias vividas. Tradução José Gradel. Rio de Janeiro: Jorge Zahar, 2008;

BEISTEGUI, Miguel de. Heidegger y lo Político. Buenos Aires: Prometeo Libros, 2013;

COSTA, Marcelo Cacinotti. O Método dos Indícios Formais de Martin Heidegger e a Contribuição da Moral como Condição de Possibilidade para uma Adequada Aplicação do Direito. 2015. Tese (Doutorado em Direito) - Programa de Pós-Graduação em Direito, Universidade do Vale do Rio dos Sinos (UNISINOS), São Leopoldo, 2015, p. 25.

DWORKIN, Ronald. O Império do Direito. Tradução Jeferson Luiz Camargo. 3. ed. São Paulo: Martins Fontes, 2014;

GADAMER, Hans-Georg. O problema da consciência histórica. Org. Pierre Fruchon; tradução Paulo César Duque Estrada, 3. ed., Rio de Janeiro: FGV, 2006;

GADAMER, Hans-Georg. Verdade e Método II: Complementos e índice. Tradução de Ênio Paulo Giachini. 5. ed. Petrópolis: Vozes, 2010;

HEIDEGGER, Martin. A Caminho da Linguagem. Tradução de Márcia Sá Cavalcante Schuback, 5. ed. Petrópolis: Vozes, 2011;

HEIDEGGER, Martin. Fenomenologia da Vida Religiosa. Tradução de Enio Paulo Giachini, Jairo Ferrandin e Renato Kirchner. Petrópolis: Vozes, 2010;

HEIDEGGER, Martin. Introdução à Filosofia. Tradução Marco Antônio Casanova. São Paulo: Martins Fontes, 2008;

HEIDEGGER, Martin. Ser e Tempo. Tradução e organização Fausto Castilho. Petrópolis: Vozes, 2012;

HEIDEGGER, Ontologia: Hermenêutica da facticidade. Tradução de Renato Kirchner. Petrópolis: Vozes, 2012;

HESSE, Konrad. A Força Normativa da Constituição. Tradução Gilmar Ferreira Mendes. Porto Alegre: Sergio Antônio Fabris Editor, 1991; 
HOMMERDING, Adalberto Narciso. Teoría de La legislación y Derecho como Integridad. Curitiba: Juruá, 2012;

INWOOD, Michael. Dicionário Heidegger. Tradução Luísa Buarque de Holanda. Rio de Janeiro: Jorge Zahar, 2002;

JULIAN, François. Fundar a Moral: Diálogo de Mêncio com um filósofo das Luzes. Tradução de Maria das Graças de Souza. São Paulo: Discurso Editorial 2001;

LIMA, Vinicius de Melo. Teoria Hermenêutica da Responsabilidade Decisória: Direitos Sociais entre Ativismo Judicial e Decisão Jurídica Democrática. Curitiba: Juruá, 2016;

LOPARIC, Zeljko. Ética e Finitude. São Paulo: EDUC, 1995;

MISSAGGIA, Juliana Oliveira. Indicações formais e a origem do método de Ser e Tempo. Revista Eletrônica Intuitio/PUCRS, Porto Alegre, v. 3, n. 1, p. 48, jun., 2010;

SAFRANSKI, Rüdiger. Heidegger, um mestre na Alemanha entre o bem e o mal. Tradução Lya Luft, São Paulo: Geração Editorial, 2005;

SCHNEIDER, Paulo Rudi. Notas sobre a relação entre indiciação formal e experiência. Natureza Humana, São Paulo, v. 14, n. 1, p. 392, 2012;

SILVA, Ovídio A. Baptista da. Processo e Ideologia: o paradigma racionalista. Rio de Janeiro: Forense, 2006;

STEIN, Ernildo. Compreensão e Finitude: Estrutura e movimento da interrogação heideggeriana. Ijuí: Unijuí, 2001;

STEIN, Ernildo. Paradoxos da Racionalidade. Porto Alegre: Pyr Edições, 1987;

STRECK, Lenio Luiz. Jurisdição Constitucional e Decisão Jurídica. 3. ed. São Paulo: Revista dos Tribunais, 2013;

STRECK, Lenio Luiz. Verdade e Consenso: Constituição, Hermenêutica e Teorias Discursivas. Da possibilidade à necessidade de respostas corretas em direito. São Paulo: Saraiva, 4. ed, 2011; 